\title{
Subclavian artery angioplasty allows for implantation of the in situ internal thoracic artery graft in patients scheduled for surgical myocardial revascularization
}

Gianluca Rigatelli, MD, FESC, FACC, a,b Massimo Giordan, MD, ${ }^{a}$ Paolo Cardaioli, MD, ${ }^{\text {a }}$ Loris Roncon, MD, ${ }^{a}$ Giuseppe Faggian, $M D,{ }^{c}$ Giorgio Rigatelli, MD, FESC, ${ }^{\mathrm{a}, \mathrm{d}}$ and

Pietro Zonzin, MD, a Verona, Italy

$\mathrm{P}$ eripheral vascular atherosclerotic distributions involving especially the supra-aortic vessels are quite prevalent. ${ }^{1}$ As a result, in patients with multivessel coronary disease including the left anterior descending (LAD) coronary artery, the left internal thoracic artery (ITA) may not be suitable as an arterial conduit because of left subclavian artery (LSA) stenosis. In such cases the alternatives are to implant a skeletonized left or right ITA graft (LITA or RITA graft), a radial artery, or a saphenous vein graft: unfortunately, all these options have a worse long-term patency rate than use of the in situ LITA. ${ }^{2}$ To improve long-term patency rate, especially in relatively young patients, the in situ LITA can be made suitable as an arterial conduit by angioplasty and stenting of the LSA. We sought to present our preliminary experience of LSA stenting to make the LITA suitable as an arterial conduit in patients with stenosis of the LSA scheduled for surgical revascularization.

From the Interventional Cardiology Unit, Division of Cardiology, Rovigo General Hospital, Italy ${ }^{\mathrm{a}}$; Endocardiovascular Therapy Research, Legnago, Verona, Italy ${ }^{\mathrm{b}}$; the Department of Cardiovascular Surgery, University of Verona Medical School, Verona, Italyc; and the Department of Specialistic Medicine, Division of Cardiology, Legnago General Hospital, Verona, Italy. ${ }^{\text {d }}$

Received for publication Jan 10, 2006; accepted for publication Jan 24, 2006.

Address for reprints: Gianluca Rigatelli, MD, FACP, FCCP, FACC, FESC, FSCAI, EndoCardioVascular Therapy Research, Via T. Speri 18, 37040 Legnago, Verona, Italy (E-mail: jackyheart@hotmail.com).

J Thorac Cardiovasc Surg 2006;131:e9-10

$0022-5223 / \$ 32.00$

Copyright (C) 2006 by The American Association for Thoracic Surgery doi:10.1016/j.jtcvs.2006.01.047

\section{Methods}

Between November 2004 and January 2006, four consecutive patients scheduled for urgent coronary surgery underwent LSA angioplasty and stenting to make the ITA suitable as an arterial conduit (Table 1). Indications for coronary surgery rather than multivessel percutaneous coronary interventions were based on left main disease or complex LAD disease and young ( $>60$ years) age. Informed consent was obtained from all patients. LSA stenting was performed via the right femoral approach with a standard Judkins right or multipurpose $6 \mathrm{~F}$ guiding catheter with a hydrophilic 0.018 inch guidewire to deploy a balloon-expandable Genesis (Cordis Inc, Johnson \& Johnson, Warren, NJ) endovascular stent (Figure 1). No protection filter device was used because no patients had signs of previous cholesterolemic embolization. After the procedure, aspirin (100 mg/day) plus low molecular weight heparin (nadroparin calcium) $100 \mathrm{IU} \cdot \mathrm{kg}^{-1} \cdot 12 \mathrm{~h}^{-1}$ were administered until the coronary surgical revascularization (usually $\leq 72$ hours).

Follow-up was accomplished by 3-, 6-, and 12-month visits and 6- and 12-month stress tests (treadmill test or nuclear stress test). Surveillance of the implanted stent was performed by 6- and 12-month Doppler ultrasonography examination or angiography with magnetic resonance imaging.

\section{Results}

The procedure was successful in all patients: no cerebral or peripheral embolism was noted after angioplasty and stenting of the LSA (Table 1). Troponin T and creatine kinase-MB remained at basal levels after the procedure in all patients despite one patient having anginal symptoms with transitory electrocardiographic myocardial ischemia requiring nitrate infusion. All four patients

TABLE 1. Clinical and procedural data of the patients

\begin{tabular}{ccllcllll}
\hline Patient & $\begin{array}{c}\text { Age } \\
\text { (y) }\end{array}$ & \multicolumn{1}{c}{ CAD } & Risk factors & EF (\%) & \multicolumn{1}{c}{ Clinical history } & $\begin{array}{c}\text { Indications to } \\
\text { intervention }\end{array}$ & $\begin{array}{c}\text { Stent (dimeter } \times \\
\text { length mm) }\end{array}$ & $\begin{array}{c}\text { Final stent } \\
\text { diameter (mm) }\end{array}$ \\
\hline 1 & 54 & LM, RCA & HPT, HY, SM & 58 & ACS, previous TIA & $80 \%$ LSA stenosis & Genesis $(6 \times 29 \mathrm{~mm})$ & 7.10 \\
2 & 50 & LM, LCX, MO & HPT, HY, SM & 68 & Recent AMI, ULI & $99 \%$ LSA stenosis & Genesis $(7 \times 29 \mathrm{~mm})$ & 8.05 \\
3 & 47 & LM, LCX, RCA & DB, HP, HY & 74 & Recent ACS & $80 \%$ LSA stenosis & Genesis $(7 \times 39 \mathrm{~mm})$ & 8.20 \\
4 & 64 & LM, RCA & HPT, HY & 51 & Recent ACS, ULI & $99 \%$ LSA stenosis & Genesis $(7 \times 39 \mathrm{~mm})$ & 8.10 \\
\hline
\end{tabular}

$\overline{A C S}$, Non-ST-elevation acute coronary syndrome; $A M I$, acute myocardial infarction; $C A D$, coronary artery disease; $D B$, diabetes; $E F$, ejection fraction evaluated by angiography; $H P T$, hypertension; $H Y$, hypercholesterolemia; $L A D$, left anterior descending coronary artery; $L C X$, left circumflex coronary artery; $L M$, left main; $L S A$, left subclavian artery; $M O$, obtuse marginal; RCA, right coronary artery; SM, smoking; TIA, transient ischemic attack; ULI, upper limb ischemia. 


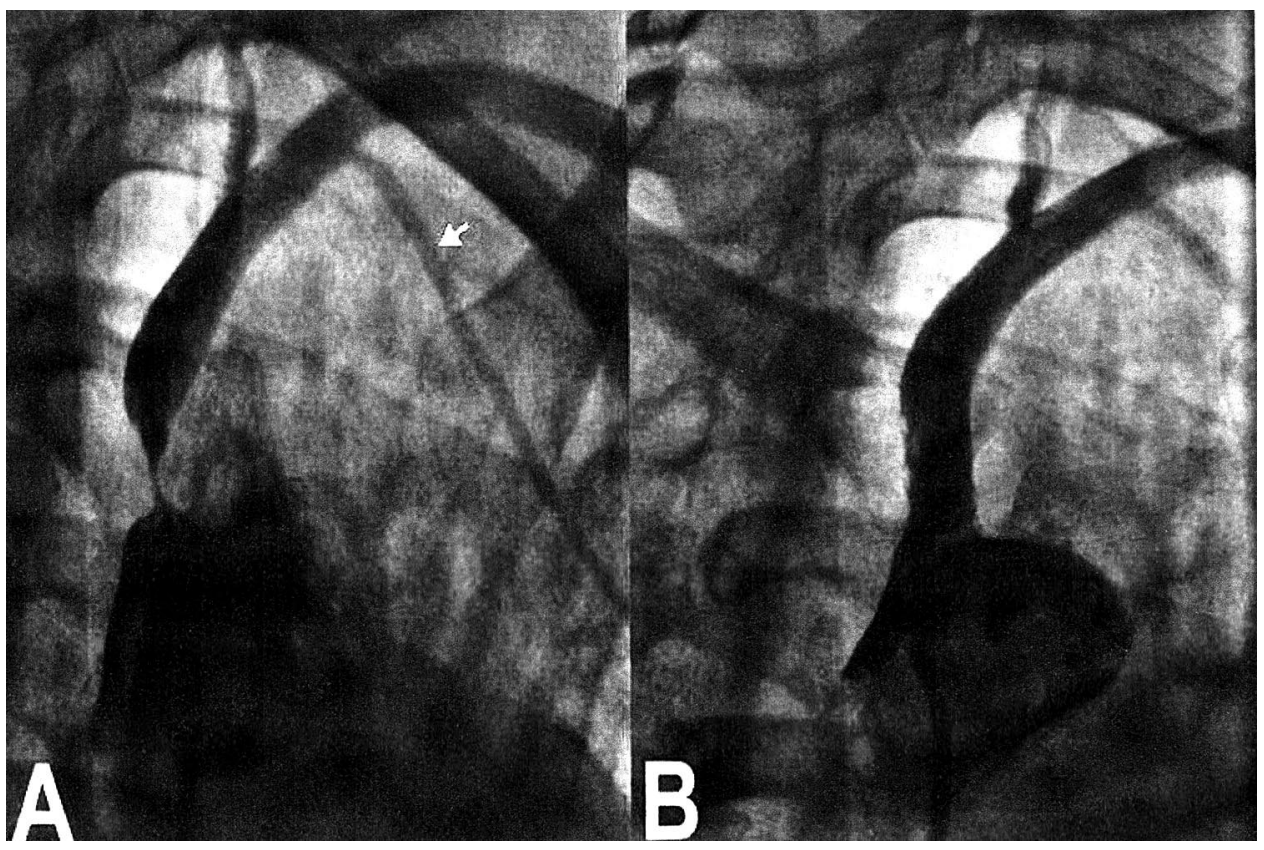

Figure 1. A, Subclavian artery tight stenosis in a female patient with 3-vessel coronary artery disease with visualization of a normal LITA (arrow). B, Result after angioplasty and stenting.

underwent successful coronary surgery with the LITA as in situ arterial conduit after 1, 2, 3, and 1 days, respectively: no patients had a cerebral ischemic attack in the preoperative period or acute limb ischemia; no patients died intraoperatively or perioperatively. At a mean follow-up of $6 \pm 4.6$ months, all patients are alive and free from angina and residual induced ischemia. On clinical and instrumental examination, no evident thrombosis or restenosis has been documented in the implanted vascular stents.

\section{Discussion}

In case of LSA stenosis, the LITA is not suitable as in situ arterial conduit and the alternatives are to use a skeletonized LITA or RITA, a radial artery, or the standard saphenous vein graft. Unfortunately, these options have a low patency rate. In a recent review, the calculated long-term patency rate was $95.9 \%$ for the LITA, $91.2 \%$ for the RITA, $90.6 \%$ for the radial artery, and $81.8 \%$ for the saphenous vein. Moreover, the patency rate differs significantly also between the in situ LITA and free-graft LITA: $96.3 \%$ versus $86.5 \%$ at 5 years. ${ }^{3}$

A not yet fully investigated option is to perform an angioplasty and stenting of the LSA to prevent any subclavian or coronary steal syndrome and make the ITA suitable as an arterial conduit. LSA angioplasty and stenting is a safe and effective procedure with a primary clinical patency rate at 5 years of $89 \%$, a local complication rate of $4.5 \%$, and a combined stroke and death rate of $3.6 \% .^{4}$ The procedure is lasting, as demonstrated by De Vries and associates ${ }^{5}$ : all clinical failures usually occur within 26 months after initial therapy, suggesting a regular follow-up for at least 2 years after percutaneous transluminal angioplasty. ${ }^{5}$

Although our very small series of patients can be considered anecdotal, it suggests that LSA angioplasty may be effective in making the LITA suitable as an arterial conduit. This strategy may be useful especially in young patients in whom the use of in situ LITA guarantees the best long-term patency rate. The proposed "light" antiplatelet regimen was well tolerated with no adverse events in terms of thrombotic or hemorrhagic effects.

\section{References}

1. Rigatelli G, Rigatelli G. Simultaneous preoperative brachiocephalic angiography and coronary angiography to prevent coronary-subclavian steal syndrome in coronary surgery candidates. Heart Surg Forum. 2005;8:E175-7.

2. Goldman S, Zadina K, Moritz T, Ovitt T, Sethi G, Copeland JG, et al. VA Cooperative Study Group \#207/297/364. Long-term patency of saphenous vein and left internal mammary artery grafts after coronary artery bypass surgery: results from a Department of Veterans Affairs Cooperative Study. J Am Coll Cardiol. 2004;44:2149-56.

3. Dion R, Glineur D, Derouck D, Verhelst R, Noirhomme P, El Khoury G, et al. Long-term clinical and angiographic follow-up of sequential internal thoracic artery grafting. Eur J Cardiothorac Surg. 2000;17:407-14.

4. Ribichini F, Maffe S, Ferrero V, Cotroneo A, Vassanelli C. Percutaneous angioplasty of the subclavian artery in patients with mammarycoronary bypass grafts. J Interv Cardiol. 2005;18:39-44.

5. De Vries JP, Jager LC, Van den Berg JC, Overtoom TT, Ackerstaff RG, Van de Pavoordt ED, et al. Durability of percutaneous transluminal angioplasty for obstructive lesions of proximal subclavian artery: longterm results. J Vasc Surg. 2005;41:19-23. 